\title{
Development and Verification of Validity of Social Adaptation Scale for Adolescents
}

\author{
Min Joo Kim ${ }^{1}$, Seung Jae $\mathrm{Oh}^{2}$, Young Kwang $\mathrm{Lee}^{3}$ \\ ${ }^{1}$ Professor, Social Welfare, Keimyung University, Republic of Korea, ju6190@kmu.ac.kr \\ ${ }^{2}$ Senior Researcher, Social Welfare, Keimyung University, Republic of Korea, osg4608@gmail.com \\ ${ }^{3}$ Deputy Director, Local Administration \& Decentralization Office, Ministry of the Interior and \\ Safety, posay1004@gmail.com
}

Corresponding author: Young Kwang Lee

\begin{abstract}
The purpose of this study is to develop a social adaptation scale for adolescents. To achieve this purpose, the first preliminary scale was derived after selecting items based on prior research and verifying the content validity of the derived 3 factors (school adaptation, family adaptation, friends adaptation) and items." In order to develop the scale, a questionnaire survey was conducted on 217 teenagers living in Daegu City, South Korea. With collected data, a confirmatory factor analysis was conducted to examine the construct validity of the preliminary scale. Through this scale development process, this study finally developed a final scale consisting of 9 items in three components that constitute adolescent social adaptation. The social adaptation scale verified and developed in this study can help adolescents to lead a more vibrant life by confirming the degree of adaptation to their families, friends, and school. Furthermore, developed scale help to verify the effectiveness of social services provided to adolescents as an important tool. The social adaptation scale developed in this study will reliably measure and evaluate the performance of social adaptation targeting adolescents, and the relationship with schools, families, and classmates will be further improved. In addition, it is expected that systematic feedback information can be provided for the organization and operation of career education courses.
\end{abstract}

Keywords: School Adaptation, Family Adaptation, Friend Adaptation, Social Adaptation Scale, The Adolescent

\section{Introduction}

Social adaptation refers to how to solve problems while interacting with the social environment, lead a stable life, maintain an independent life that can satisfy oneself, and adapt to society in harmony with the social environment through personal and social independence. It also shows the ability to learn and live as a member of society. In particular, social adaptation refers to the state of adjustment that exists between an individual's environment or the process of adjustment that creates such a state. Therefore, adaptation to school becomes school adaptation, adaptation to work becomes workplace adaptation, and adaptation to society becomes social adaptation. In other words, the area of adaptation is first, adaptation to work or school, second, adaptation to social activities, third, adaptation as parents, fourth, adaptation as spouse, fifth, adaptation with relatives, sixth, adaptation to family, etc. It can be classified in many different ways.

To adolescents, unlike adults, social adaptation refers to adaptation to school, which represents the

Received: April 10, 2021; $1^{\text {st }}$ Review Result: May 27, 2021; $2^{\text {nd }}$ Review Result: July 14, 2021

Accepted: August 30, 2021 
most important adaptation to school life, adaptation to friends, which represents the most important relationship with friends during adolescence, and adaptation to family, which represents relationships between families experienced during adolescence. Therefore, in this study, social adaptation targeting adolescents was classified into school adaptation, friend adaptation, and family adaptation. The period of adolescents can be said to be a period of growth as well as a period of experiencing physical, social, and environmental changes. Therefore, it can be said that it is very important for adolescents to grow up healthy not only for individuals but also for society as a whole. In order for adolescents to grow up as healthy members of society, the surrounding environment is important, and in particular, they should pay attention to the relationship and adaptation to school, family, and friends.

The purpose of this study is to develop a social adaptation scale that can measure the degree of adaptability to school, friends, and family recognized by adolescents. Based on the social adaptation scale developed through this study, the degree of social adaptation recognized by adolescents can be confirmed. In particular, the identified level of social adaptation can be used as important data to improve the effectiveness of social service programs provided to improve the social adaptation of youth. As for social services targeting adolescents, it is important to improve the social adaptation of adolescents, so all social service projects or programs can improve the effectiveness of services by measuring the degree of social adaptation of youth users.

\section{Theoretical Background}

\subsection{Concept of Social Adaptation and Necessity to Develop of Social Adaptation Scale}

Adjustment, in the general dictionary meaning, is 'adjustment or adaptation to certain conditions or circumstances', or 'psychologically the environment and life are in harmony, or in such a state'[1]. Therefore, adaptation means a harmonious relationship between the individual and the environment. The individual adapts himself to his own needs and environment and gets along well without friction. Humans are socialized, grown, and developed in social relationships. As a social animal, humans begin to form close relationships with family members such as parents and siblings in the early stages of life, and gradually expand social relationships by forming new relationships with adults and peers other than family members as age increases[2]. In this relationship, adaptation emerged as a social term that refers to humans taking appropriate actions or attitudes toward the environment. In the case of human beings, in order to lead a social life, they must not only adapt to the natural environment, but also live by adapting to social environments such as groups, social systems, and human relationships. Adaptation in the general sense consists of two kinds of processes; adapting oneself to a given environment, and actively changing the environment to satisfy one's needs. In this respect, good adaptation means acting voluntarily, taking risks, and making the most of the environment rather than throwing yourself to the environment as an active relationship between the individual and the social environment including family members[3].

The reinforcement of adaptation and adjustment to school, family, community, and work of social service users participating in the services provided by the government can be said to be the direct effect of social service provision. Among the social service programs, domestic care services provided to persons with disabilities or diseases, maternal newborn services, child emotional development support services or child psychological emotional services provided as part of a community service investment program, the elderly's social participation or social intervention programs, and various sports and leisure services are all aimed at overcoming the alienation of users from society, isolation or exclusion from family and society through the provision of social services. Since overcoming social isolation or exclusion can be overcome by reinforcing adaptability and adaptability to society or family, social services eventually reinforce users' social adaptation and adaptability, thereby emphasizing their 
problem solving. In social service program, social adaptation refers to the degree of ability of users to adapt to society.

Looking at scholars' definition of adaptation, Piaget (1952)[4] viewed the adaptation process of an individual as assimilation and control. He said that adaptation is simply a creative process in which realistic goals are set and achieved by accurately grasping dynamic relationships with the environment. Gates (1950)[5] regarded adaptation as a harmony between an individual's internal adaptation and an external adaptation of society, and said that personally, it is overflowing with happiness, and that socially, it is to effectively and efficiently solve the immediate problems. Moorehouse (1991)[6] defined the concept of adjustment as the ability to interact and cooperate with family members and peers, and the ability to cope with the demands of one's responsibilities or the demands of appropriate behavior. Allport (1961)[7] defined adaptation as a voluntary and creative action to the environment, and as an essential condition, actions and results give individuals a sense of stability and conform to social values and order. Germain \& Gitterman (1979)[8] also refers to adaptation as a concept representing the relationship between the individual and the environment, in which an individual's active effort to achieve a goodness of fit in order to fulfill his or her lifelong survival, growth, and productive functions. Kim (2001)[9] also describes adaptation as a process in which an individual changes the environment to suit his or her own needs as a process that takes place through active exchanges between the individual and the environment, and adapts to such changes in the environment. Therefore, an adapted state means that an individual feels satisfied without frustration or anxiety in his or her own life by reasonably solving all problems arising from daily life and satisfying or controlling one's own needs under the constantly changing social environment or social conditions[10].

According to the definition of social adaptation, social adaptation is the ability to adapt to the social environment in a rational and beneficial direction, and it also refers to the state of adjustment that exists between the environment in which an individual is located. It also means the process of adjustment[11]. Therefore, in terms of healthy ego function, a healthy and successful social adaptation is a social ego (social ego: an individual's belief in one's self in society) that maintains a smooth relationship between social Id (instinct) and social super ego. In terms of scholars' definition of social adaptation, Shaffer (1956)[12] defined social adaptation as a harmony between individual needs and society and environment, citing the theory of desire dissatisfaction. Adams (1972)[13] defined as an individual's ability to respond and effectively adapt to society and environment. Sage (1974)[14] saw social adaptation as the process of becoming a member of society by learning the cultural attitudes, values, and roles of the group to which an individual belongs, And Cavell (1990)[15] viewed social adaptation as one of the constituent areas that constitute social competence, and defined how socially an individual expands and achieves valid goals as social adaptation.

In Korea, Kim et al. (2012)[16] described adaptation as two types of processes. First, adaptation is a process of adapting oneself to a given environment, and second, it is defined as a process of changing the environment in order to satisfy one's needs. Oh (1999)[17] viewed social adaptation as a process in which humans adapt themselves to a given environment and actively change the environment in order to meet their own needs and desires.

In other words, she regarded it as an ability to live as a member of society by learning how to adapt to the society to which they belong, as an individual's ability to harmonize with the social environment to which they belong. In the study of Kang (2003)[18], social adaptation was viewed as the ability to tolerate changes in the social environment and respond appropriately to them[19].

Based on this concept of adaptation and social adaptation, it can be seen that social adaptation reflects a sense of belonging to society and needs of society, and implies recognition of the role of social norms and ethical values. In other words, it is a process that satisfies an individual's mental abilities and skills, physical, social and environmental needs, and requires appropriate qualities, which includes the characteristics of emotional stability and interpersonal relationships[20]. In addition, it can be said that 
the social adaptation is a concept meaning an individual changes and depends on the influence of other people at various levels, i.e., family, co-workers, local communities, and the society[21]. In sum, social adaptation is to solve problems while interacting with the social environment, to live a stable life, and to maintain an independent life that can satisfy oneself. Furthermore, through personal and social independence, social adaptation is in harmony with the social environment and it can be seen as the ability to learn how to adapt and live as a member of society.

After all, social adaptation is an essential ability for all citizens to cope with an independent life and environment. People with low social responsiveness have a low ability to cope with social life and environmental changes, making it difficult to adapt themselves to society, and furthermore, it may be difficult to maintain a satisfactory life. Therefore, it is necessary to provide various social services to maintain and improve social adjustment. In particular, it can be said that one of the important goals of social service programs is to improve the social adaptability of social service users of socially vulnerable groups such as the elderly, the disabled, and adolescents. Therefore, in terms of reinforcing autonomy that enables social service users to live independent and active lives as members of society, the improvement of social adaptation can affect users of social service programs, including the elderly, the disabled, and low-income residents and the youth. That is, improvement of social adaptation for the social service users is the main service effectiveness.

\subsection{Literature Review about the Measurement of Social Adaptation}

Despite the importance of adolescents' adaptation to school, friends and family research on measuring tools for adolescents' social adaptation is limited, and most studies on measuring tools for social adaptation have been conducted with adults. A measuring tool for the degree of social adaptation in adults was first developed by Weissman and Bothwell (1976)[22] of the United States. They presented the Self-Report Social Adjustment Scale, which is directly written by individuals themselves, which consists of 42 question items. In particular, they measured social adaptation in the last two weeks in seven areas: work life, social and leisure activities, relationship with relatives, role as spouse, role of parents, relationship with family, and economic relevance (difficulty). It is a 5-point Likert scale, and the higher the score, the more severe the maladjustment.

Weissman and Bothwell's social adaptation scale was adapted to fit the characteristics of the UK, which was developed by Cooper and colleagues in 1982. The scale they developed consists of 45 questions in a total of six areas, excluding economic difficulties, and is a five-point Likert scale that measures the experiences over the past two weeks, similar to the Weissman and Bothwell scales. The advantage of the scale developed by Panella and colleagues (1982)[23] is that a single measurement tool for social adaptation includes all measurement questions that measure adaptability to family, society, work, and school. The social adaptation scale of Cooper and his colleagues is a 5-point scale, and the answer is 1 point $=$ always yes, 2 points $=$ mostly yes, 3 points $=$ half so, 4 points $=$ generally not, 5 points $=$ not at all. The higher the score, the more severe the maladjustment is.

\subsection{The Social Adaptation Measurement for the Adolescents and its Components}

In this study, in order to operationalize the concept of social adaptation before developing a social adaptation scale that can be applied to adolescents, it is defined as follows based on previous studies. Social adaptation is "the ability to live as a member of society interacting with the social environment to solve problems, lead a stable life, maintain an independent life that can satisfy oneself, and learn how to adapt to society in harmony with the social environment through personal and social independence". In order to measure social adaptation, it is important to identify the dimensions consisting of social adaptation. Based on the concepts proposed by Panella and colleagues (1982)[23], social adaptation 
components are; first, adaptation to work or school, second, adaptation to social activities, third, adaptation as parents, fourth, adaptation as spouse, fifth, adaptation to relatives, and sixth, adaptation to family. However, in order to apply this components as social adaptation for adolescents, a new component should be needed.

The research on the adaptation of adolescents in Korea so far has mainly focused on the study of school adaptation, the study of resilience, and the study of family support rather than social adaptation. Representative studies include[24][25]. In addition, many studies have been conducted on the importance of parental and friend relationships as a result of adaptation to relationships in adolescence, and representatively, there are studies by [19][20][26]. These studies emphasize that parental relationships, school adaptation, and friend adaptation are important environmental factors for adolescents.

The social adaptation of adolescents and adults should be classified because the given circumstances are different, but until now, no research has been conducted on the elements or measuring tools that explain the social adaptation of adolescents. Therefore, in this study, the constituent elements of adolescent social adaptation were derived through prior studies on the adaptation of adolescents and social adaptation studies conducted on adults. In particular, in order to develop a scale to measure the degree of social adaptation of adolescents, in this study, based on the concept suggested by Cooper and colleagues, the dimension to constitute social adaptation are divided by three, first, adaptation to school, and second, adaptation to friends and third, adaptation to family. As adolescents prioritize stability in school life rather than social life, work or social adaptation can be measured as school adaptation. In addition, adaptation to relatives, spouses, and parents was unified as family adaptation suitable for adolescents, and friend adaptation was added in consideration of the importance of companionship, a characteristic of adolescence. The measuring components according to the elements of youth social adaptation suggested by this study are as follows.

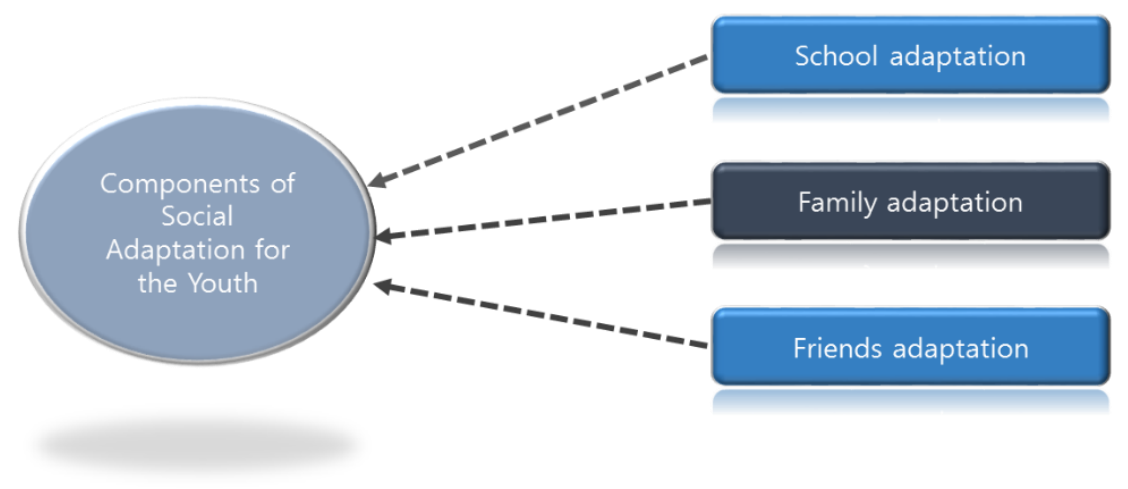

[Fig. 1] Measuring Components of Social Adaptation for the Youth

\section{Research Method}

\subsection{The process of Social Adaptation Scale Development}

In order to develop a social adaptation scale for adolescents, in this study, a survey was conducted using a preliminary social adaptation scale derived by randomly selected 300 students from elementary to high schools living in Daegu City. The survey was conducted face-to-face to 242 students, and the response rate to the questionnaire was $80 \%$, of which a total of 217 questionnaires were used, excluding 25 questionnaires with unscrupulous answers. The questions on the social adaptation scale for adolescents are consisted of 20 questions in three areas: school adaptation (6 questions), friend 
adaptation (9 questions), and family adaptation (5 questions) based on previous studies. Based on the derived scale, the content validity was reviewed through a focus group interview with 6 experts related to youth welfare (three professors in the Department of Social Welfare and three experts in the field of youth welfare). Four questions were revised and supplemented to derive the first social adaptation preparatory scale consisting of a total of 19 question items. The final drawn preliminary scale for social adaptation was composed of a 7-point Likert scale, and the question items are as follows.

[Table 1] The Preliminary Scale for Social Adaptation

\begin{tabular}{|c|c|c|}
\hline Domain & Number & Questions about Social Adaptation \\
\hline \multirow{6}{*}{$\begin{array}{l}\text { School } \\
\text { adaptation }\end{array}$} & 1. & Have you missed school in the last two weeks? \\
\hline & 2. & Did you do well at school in the past two weeks? \\
\hline & 3. & Have you ever felt ashamed of what you did at school in the past two weeks? \\
\hline & 4. & $\begin{array}{l}\text { In the last two weeks, have you ever been angry with students or classmates from the same } \\
\text { school? }\end{array}$ \\
\hline & 5. & $\begin{array}{l}\text { During the past two weeks, have you ever felt agitated by worrying about your academic } \\
\text { performance? }\end{array}$ \\
\hline & 6. & Have you enjoyed your school life in the past two weeks? \\
\hline \multirow{9}{*}{$\begin{array}{l}\text { Friends } \\
\text { adaptation }\end{array}$} & 7. & Have you met a friend in the last two weeks? \\
\hline & 8. & Have you talked openly with a friend in the past two weeks? \\
\hline & 9. & $\begin{array}{l}\text { During the past two weeks, did you and your friends engage in social activities such as going out, } \\
\text { visiting institutions, or watching movies? }\end{array}$ \\
\hline & 10. & $\begin{array}{l}\text { During the past two weeks, have you spent time with your friends on work or hobbies that interest } \\
\text { you? }\end{array}$ \\
\hline & 11. & Have you ever been angry with a friend in the last two weeks? \\
\hline & 12. & Have you ever been hurt by a friend in the past two weeks? \\
\hline & 13. & $\begin{array}{l}\text { During the past two weeks, have you ever been easily nervous, embarrassed, or sick when } \\
\text { meeting people? }\end{array}$ \\
\hline & 14. & $\begin{array}{l}\text { In the past two weeks, have you ever felt lonely or wanted to socialize with other students besides } \\
\text { your friends? }\end{array}$ \\
\hline & 15. & Have you ever felt bored in your free time in the past two weeks? \\
\hline \multirow{4}{*}{$\begin{array}{l}\text { Family } \\
\text { adaptation }\end{array}$} & 16. & In the past two weeks, have you ever been more concerned about problems with your family? \\
\hline & 17. & In the past two weeks, have you ever felt that you made your family gloomy? \\
\hline & 18. & In the past two weeks, have you ever felt that your family has made you gloomy? \\
\hline & 19. & Have you ever quarreled or screamed with your family in the past two weeks? \\
\hline
\end{tabular}

\subsection{Data Analysis}

This study used the following data analysis method in developing the social adaptation scale.

First, the number of factors was determined based on the theoretical background and previous research on social adaptation, and on the basis of this, items were extracted around the factors constituting social adaptation. In addition, a revised and supplemented preliminary scale was derived through expert interviews to verify the content validity of the extracted factors and questions. Second, among the items extracted through confirmatory factor analysis targeting the preliminary scale for which factors and variables were first determined, variables that were difficult to classify into any factor or factors that hinder model fit were removed. The reason for attempting confirmatory factor analysis without going through exploratory factor analysis was that the number of common factors of the social adaptation scale was extracted as 3, after the theoretical background of social adaptation and the process of exploration through previous research analysis and because the common factors were confirmed and the question items were revised and supplemented from the experts. In other words, it can be said that the constituent 
factors of social adaptation for adolescents were determined in advance without going through exploratory factor analysis.

In sum, in order to verify the validity of the first preliminary scale for social adaptation, which was modified for the social service project for children and adolescents, the three areas derived through a slight correction and supplementation process for existing question items according to the nature of the social service program. For the first preliminary scale consisting of 19 question items, the exploratory process is omitted and only the method of confirmatory factor structure is used. The data analysis process for the development of the social adaptation scale is as the following.

First, a reliability analysis was conducted through the Cronbach's $\alpha$ to verify the degree of internal consistency between each factor.

Second, the correlation between each factor was analyzed for the items derived from the factor analysis.

Third, by using the maximum likelihood method for the derived items, a confirmatory factor analysis was performed to confirm the explanatory power and fitness index of the question items.

Fourth, the convergent validity of the scale with confirmed fit was verified by using a method based on the convergent reliability (CR) value. And the discriminant validity was evaluated two standard error interval estimates on the scale.

\section{The Result of the Study}

\subsection{General Characteristics of Survey Participants}

The general characteristics of participants in the social adaptation scale survey for adolescents are as follows. The gender was 108 males (49.8\%) and 109 females (50.2\%). As for the age, elementary school students 5 (2.4\%), middle school students $58(26.7 \%)$, and high school students 154 (70.9\%). As for the region, Jung-gu had 3 (1.4\%), Dong-gu had 48 (22.1\%), Seo-gu had 23 (10.6\%), Nam-gu had 21 (9.7\%), Buk-gu had 10 (4.6\%), and Suseong-gu had 49 (22.6\%), Dalseo-gu, 36 (16.6\%), and Dalseong-gun, 27 (12.4\%).

\subsection{Descriptive Statistics and Correlation}

The results of the correlation analysis between the three factors are shown. First, looking at the descriptive statistical analysis by factors, the mean of school adaptation was 5.65, the standard deviation was 1.13 , the mean of friend adaptation was 5.35 , the standard deviation was 1.16 , the mean of family adaptation was 5.70, and the standard deviation was 1.45. As a result of correlation analysis, it was found that the social adaptation scale was statistically significant $(\mathrm{p}<.01)$ between the three factors of the preliminary question. In detail, the correlation between friend adaptation and school adaptation was .757 $(\mathrm{p}<.01)$, family adaptation and school adaptation $.629(\mathrm{p}<.01)$, and family adaptation and friend adaptation were $.717(\mathrm{p}<.01)$.

\subsection{Reliability}

Reliability analysis was conducted to verify the degree of internal consistency between each factor for 19 questions of three factors, and the results are shown in [Table 2]. Cronbach's $\alpha$ of school adaptation was .791 , friend adaptation was .836 , and family adaptation was .904 .

In general, if the Cronbach's $\alpha$ coefficient is more than .60, it is considered that reliability is secured. Therefore, reliability was secured for 19 items of three factors. 
[Table 2] Reliability Analysis Result of Preliminary Question on Social Adaptation Scale

$(\mathrm{N}=217)$

\begin{tabular}{|c|c|c|c|c|}
\hline Factor & $\begin{array}{l}\text { Question } \\
\text { Number }\end{array}$ & $\begin{array}{l}\text { Cronbach's } \\
\text { Each factor }\end{array}$ & total & items \\
\hline \multirow{6}{*}{$\begin{array}{c}1 \text { Factor } \\
\text { (School Adaptation) }\end{array}$} & Q1 & .757 & \multirow{6}{*}{.791} & \multirow{6}{*}{6} \\
\hline & Q2 & .773 & & \\
\hline & Q3 & .725 & & \\
\hline & Q4 & .746 & & \\
\hline & Q5 & .713 & & \\
\hline & Q6 & .768 & & \\
\hline \multirow{9}{*}{$\begin{array}{c}2 \text { Factor } \\
\text { (Friend Adaptation) }\end{array}$} & Q7 & .826 & \multirow{9}{*}{.836} & \multirow{9}{*}{9} \\
\hline & Q8 & .841 & & \\
\hline & Q9 & .822 & & \\
\hline & Q10 & .823 & & \\
\hline & Q11 & .811 & & \\
\hline & Q12 & .810 & & \\
\hline & Q13 & .810 & & \\
\hline & Q14 & .814 & & \\
\hline & Q15 & .811 & & \\
\hline $\begin{array}{c}3 \text { Factor } \\
\text { (Family Adaptation) }\end{array}$ & Q16 & .910 & .904 & 4 \\
\hline
\end{tabular}

\subsection{Confirmatory Factor Analysis}

In order to secure the validity of the factor structure for the preliminary questions on the social adaptation scale whose internal validity was verified, a confirmatory factor analysis was conducted using the AMOS 21.0 statistical program. The confirmatory factor analysis is used to prove the validity of the data, and the data is verified by the confirmatory factor analysis so that more reliable conclusions can be reached. In general, since most of the variables used in the research model are measured in multiple items, it is important to secure single-dimensionality.

Confirmatory factor analysis aims to secure single dimensionality, and it is an analysis method in which questions that measure the factor are assigned to each factor in advance. The figure below shows the final model analyzed using the structural equation model.

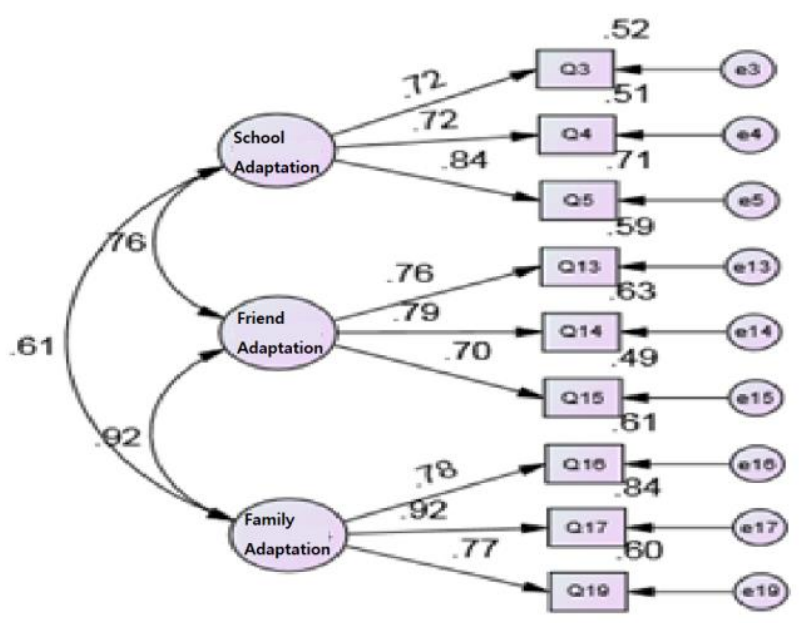

[Fig. 2] Confirmatory Factor Analysis Model for Social Adaptation Scale 
This is the result of confirmatory factor analysis for 19 items of 3 factors. After removing 10 items with low explanatory power from 19 questions (3 questions for school adaptation: Q1, Q2, Q6, 6 questions for adaptation to friends: Q7, Q8, Q9, Q10, Q11, Q12, 1 question for family adaptation: Q18). As a result, a confirmatory factor analysis was conducted using 9 items. The absolute fit index was found to be $\chi^{2}=54.728(\mathrm{df}=24), \mathrm{p}=.000, \mathrm{GFI}=.953$, and RMSEA=.077. As a result of examining the absolute fit index, the $\chi^{2}$ verification, RMSEA, and GFI values were all found to be appropriate. RMSEA should be less than .08, and GFI closer to 1 can be interpreted as good fit[27]. The incremental fit index was $\mathrm{IFI}=.971$, TLI $=.956, \mathrm{CFI}=.971$, which was more than .90 , so the overall model fit was appropriate. The parsimony fit Index was found to be PNFI=.633, PCFI=.647, and AGFI=.911. PNFI and PCFI should be higher than .60, and AGFI can be interpreted the better fit as being closer to 1. Comprehensively examining the model fit, it can be interpreted that the fit of the measurement model is generally good, and that the measurement model fits the data well.

The analysis results of the final research model are shown in [Table 3]. In the final model, the standardized regression coefficient and covariance between the measured variable and the factor were all statistically significant $(\mathrm{p}<.001)$. In addition, the loads of the standardized regression coefficients were all over .50 .

[Table 3] The Final Model Factor Analysis of Social Adaptation Scale

\begin{tabular}{|c|c|c|c|c|c|c|}
\hline & & & & & & $(\mathrm{N}=217)$ \\
\hline & & & Estimate & S.E. & C.R. & $\mathrm{P}$ \\
\hline Q3 & $\leftarrow$ & School Adaptation & 1.000 & & & \\
\hline Q4 & $\leftarrow$ & School Adaptation & 1.258 & .134 & 9.384 & $* * *$ \\
\hline Q5 & $\leftarrow$ & School Adaptation & 1.366 & .132 & 10.374 & $* * *$ \\
\hline Q13 & $\leftarrow$ & Friend Adaptation & 1.000 & & & \\
\hline Q14 & $\leftarrow$ & Friend Adaptation & 1.005 & .084 & 11.898 & $* * *$ \\
\hline Q15 & $\leftarrow$ & Friend Adaptation & .974 & .095 & 10.300 & $* * *$ \\
\hline Q16 & $\leftarrow$ & $\begin{array}{l}\text { Family } \\
\text { Adaptation }\end{array}$ & 1.000 & & & \\
\hline Q17 & $\leftarrow$ & $\begin{array}{l}\text { Family } \\
\text { Adaptation }\end{array}$ & 1.059 & .073 & 14.471 & $* * *$ \\
\hline Q19 & $\leftarrow$ & $\begin{array}{l}\text { Family } \\
\text { Adaptation }\end{array}$ & .911 & .076 & 12.036 & $* * *$ \\
\hline
\end{tabular}

\subsection{Validity Verification}

\subsubsection{Convergent Validity}

Convergent validity, also called concentrated validity, indicates that there must be a high correlation between values measured by different methods in order to measure the same concept. In this study, a method based on the value of convergent reliability (CR) was used to verify the validity of convergence. If the CR value is more than 0.7 , it is interpreted as having convergence validity[28]. The reliability of the latent factors appeared in this study was school adaptation .749, friend adaptation .750, and family adaptation .749 , and since all values were over 0.7 , convergent validity was secured.

\subsubsection{Discriminant Validity}

Discriminant validity is based on the premise that there must be clear differences in measurements 
between different variables. In other words, it can be said that discriminant validity is secured only when the correlation between one variable and the other is low. In this study, two standard error interval estimates, a criterion for verifying discriminant validity, were used. Since the discriminant validity using the standard error estimation interval equation can be said to be secured only when the correlation between the variables is low, it is necessary to find out whether the hypothesis that the variables are the same can be rejected (Fornel and Larcker, 1981). The coefficient of adaptation to friends and adaptation to family was .918, and the corresponding standard error (S.E) was .228. The coefficient of adaptation to friends and adaptation to family was .918 , and as a result of substituting the corresponding standard error of .228 , the values were $1.374, .462 \neq 1$. In other words, discriminant validity was secured because the hypothesis that the variables were the same was rejected.

The final questions of the social adaptation scale derived through the process of confirmatory factor analysis and validation are 9 questions in total: 3 questions for school adaptation, 3 questions for friend adaptation, and 3 questions for family adaptation, and the final questions are as shown in [Table 4]. As a result of conducting a reliability analysis based on the final question, it was found that Cronbach's $\alpha$ $=.796$ for school adaptation, Cronbach's $\alpha=.795$ for friend adaptation, and Cronbach's $\alpha=.857$ for family adaptation. Reliability was secured in 3 questions for social adaptation scale, 3 questions for friend adaptation, and 3 questions for family adaptation.

[Table 4] Final Questions on the Social Adaptation Scale for the Adolescent

$(\mathrm{N}=217)$

\begin{tabular}{llll}
\hline Factor & $\begin{array}{l}\text { Question } \\
\text { number }\end{array}$ & Questions & Items \\
\hline
\end{tabular}

Q3 Have you ever felt ashamed of what you did at school in the past two weeks?

$\begin{aligned} & \text { School } \\ & \text { adaptation }\end{aligned}$
Q4 $\quad \begin{aligned} & \text { During the past two weeks, have you ever been angry with students or classmates } \\ & \text { from the same school? }\end{aligned}$
Q5 $\quad \begin{aligned} & \text { During the past two weeks, have you ever felt agitated by worries about your } \\ & \text { academic performance? }\end{aligned}$

\begin{tabular}{|c|c|c|c|}
\hline \multirow{3}{*}{$\begin{array}{l}\text { Friends } \\
\text { adaptation }\end{array}$} & Q13 & $\begin{array}{l}\text { During the past two weeks, have you ever been easily nervous, embarrassed, or } \\
\text { sick when meeting people? }\end{array}$ & \multirow{3}{*}{3} \\
\hline & Q14 & $\begin{array}{l}\text { In the past two weeks, have you ever felt lonely or wanted to socialize with other } \\
\text { students besides your friends? }\end{array}$ & \\
\hline & Q15 & Have you ever felt bored in your free time in the past two weeks? & \\
\hline \multirow{3}{*}{$\begin{array}{l}\text { Family } \\
\text { adaptation }\end{array}$} & Q16 & $\begin{array}{l}\text { During the past two weeks, have you ever been more worried about problems with } \\
\text { your family? }\end{array}$ & \multirow{3}{*}{3} \\
\hline & Q17 & In the past two weeks, have you ever felt that you made your family gloomy? & \\
\hline & Q19 & Have you ever quarreled or screamed with your family in the past two weeks? & \\
\hline
\end{tabular}

The process of confirmatory factor analysis and the stages of development of the social adaptation scale through validity verification are 19 questions in the preliminary questions for the social adaptation scale, and as a result of conducting a confirmatory factor analysis, 10 items were removed. Finally, the social adaptation scale was composed of 9 questions, and it was divided into 3 factors. 


\section{Conclusion}

The purpose of this study is to develop a social adaptation scale that can measure adolescents' social adaptation. In order to achieve the above research goal, items were selected based on prior research and factor analysis was conducted. Therefore, in this study, the item judged to be incompatible with the social adaptation scale was removed, and finally, a scale composed of 9 items in three areas was developed. In addition, convergent validity and discriminant validity analysis were conducted to verify the construct validity of the developed scale. As a result of the analysis, the validity was secured. As a result of the final analysis, a youth social adaptation scale composed of three factors and a total of nine items was developed.

The social adaptation scale for the adolescent, developed through this study and verified for validity, will serve as an important basic data for identifying and solving various problems of growing youth. In particular, it can be a useful resource to help adolescents grow into correct members of society by checking the degree of adaptation to school, friends, and family relationships. In addition, it can be expected that it will help to confirm the achievement of the goals and limitations of social service programs for youth, and to prove the effectiveness of the service. The limitations of this study are as follows. In order to develop a social adaptation scale, it is difficult to guarantee representativeness because data was collected for adolescents receiving social services in D city, Korea. In future followup studies, it is proposed to collect and study data from respondents from other regions.

\section{References}

[1] National Institute of Korean Language, Standard Korean Ambassador, Korea: Doosan Dong-A Publishing, (1999)

[2] D. S. Yeon, The Effect of Sports Activity Participation Level of Ego-Identity and Social Relationship of Late Adolescents, The Korean Journal of Physical Education, (2003), Vol.42, No.6, pp.211-221.

[3] Y. B. Kim, S. M. Yoon, The Effects on the Social Adijustment to Participation in Swimming Program of the Elderly with Osteoarthritis, Korea Sport Research, (2007), Vol.18, No.1, pp.449-458.

[4] J. Piaget, The Origins of Intelligence in Children, London: International Universities Press, (1952)

[5] A. Gates, A Management Approach to Problems of Individual Adjustment, Archives of industrial hygiene and occupational medicine, (1950), Vol.2, No.2, pp.202-226.

[6] M. J. Moorehouse, Linking maternal employment patterns to mother-child activities and children's school competence, Developmental Psychology, (1991), Vol.27, No.2, pp.295.

[7] G. W. Allport, Patterns and growth in personality, New York: Holt, Reinhart \& Winston, (1961)

[8] C. B. Germain, A. Gitterman, The life model of social work practice, Social work treatment: Interlocking theoretical approaches, UK: Oxford University Press, (1979)

[9] S. K. Kim, A study of psychosocial adaptation of adolescents in group homes, Ewha Womans University, Doctoral Dissertation, (2001)

[10] M. H. Woo, A study on the social adaptation of adolescent children of single-parent families, Sungshin Women's University, Doctoral Dissertation, (2009)

[11] S. H. Park, Effect of Multi-cultural Family' Social Adjustment Ability on Satisfaction through Cultural Tourism, DongMyung University, Doctoral Dissertation, (2011)

[12] L. F. Shaffer, E. J. Shoben, The psychology of adjustment, Boston: Houghton Mifflin, (1956) 
[13] H. E. Adams, Psychology of adjustment, Ronald Press Company, (1972)

[14] G. Sage, Sport and American society: Selected readings(2nd ed.), MA: AddisonWesley, (1974)

[15] T. A. Cavell, Social adjustment, social performance, and social skills: A tri-component model of social competence, Journal of Clinical Child Psychology, (1990), Vol.19, No.2, pp.111-122.

[16] H. T. Kim, S. Yi, J. H. Jeon, M. Bang, Factors Relating Group Home Family Affecting Psycho-social Adaptation of Group Home Children Factors Relating Group Home Family Affecting Psycho-social Adaptation of Group Home Children, Journal of School Social Work, (2012), Vol.22, pp.1-22.

[17] H. K. Oh, Social Welfare Practice with the Disabled, Korean: Asia Media Research, (1999)

[18] S. W. Kang, The Relationships among Exercise Addiction, Self-Consciousness, and Social Adjustment in Life Sports Participants, The Korean Journal of Physical Education, (2003), Vol.42, No.5, pp.91-99.

[19] S. K. Lim, H. S. Lee, The Effects of Self-esteem, Relationships with Parents and Peer Relationships on Adolescents' School Adjustmen, Journal of Korean Home Economics Education Association, (2007), Vol.19, No.3, pp.169-183.

[20] H. Y. Shin, Adolescents' social dominance goals and social adjustment behavior: The moderating role of friendship quality, The Korean Journal of Developmental Psychology, (2020), Vol.33, No.4, pp.1-18.

[21] K. S. Ko, A Study on the Factors Influencing the Psychological and Social Adaptation of Koryuin in Kore, Seoul Christian University, Doctoral Dissertation, (2011)

[22] M. M. Weissman, S. Bothwell, Assessment of social adjustment by patient self-report, Archives of General Psychiatry, (1976), Vol.33, No.9, pp.1111-1115.

[23] D. H. Panella, P. F. Cooper, S. W. Henggeler, Peer relations in adolescence, Delinquency and adolescent psychopathology: A family-ecological systems approach, Littleton, MA: Wright-PSG, (1982)

[24] Y. M. Oh, G. M. Lee, Effects of Solution-focused Group Art Therapy Programs on the Level of School Adaptation and Problem Solving Ability of School Maladapted Adolescence, Journal of Emotional \& Behavioral Disorder, (2020), Vol.36, No.2, pp.169-189.

[25] H. R. Lee, H. I. Jo, A Validation Study of the Resilience Scalein Korean Adolescents, The Korean Journal of Counseling and Psychotherapy, (2006), Vol.18, No.2, pp.353-371.

[26] H. M. Roh, W. S. Choi, I. J. Park, The Effects of Children's Self-Regulation on their Friendships and School Adjustment, Journal of Korean Home Management Association, (2009), Vol.27, No.2, pp.281-292.

[27] M. W. Browne, R. Cudeck, Alternative ways of assessing model fit, Sociological Methods \& Research, (1992), Vol.21, No.2, pp.230-258.

[28] E. G. Ji, M. J. Kim, Development and practice of Social Welfare Measurement, Korea: Hakjisa, (2015) 